\title{
ОСОБЕННОСТИ САМООТНОШЕНИЯ СТУДЕНТОВ ВУЗА, ЗАНИМАЮЩИХСЯ И НЕ ЗАНИМАЮЩИХСЯ СПОРТОМ, В СВЯЗИ С САМОВОСПРИЯТИЕМ ФИЗИЧЕСКОЙ И ЭСТЕТИЧЕСКОЙ МОДАЛЬНОСТЕЙ Я-ОБРАЗА
}

\author{
Каринэ А. Бабиянц, ${ }^{1 *}$, Елена В. Коломийченко ${ }^{1}$ Ислам С. Хажуев \\ ${ }^{1}$ Южный федеральный университет, г. Ростов-на-Дону, \\ Российская Федерачия \\ 2 Чеченский государственный педагогический университет, г. Грозный, \\ Российская Федерация \\ *E-mail: rgupsyf@inbox.ru
}

Статья посвящена исследованию психологических особенностей самоотношения у студентов вуза, занимающихся и не занимающихся спортом. Рассматриваются особенности самовосприятия у студентов, занимающихся гендерно специфичными и гендерно неспецифичными видами спорта посредством таких категорий Я-образа, как Я-физическое и Я-эстетическое. Доказывается влияние телесного восприятия Я-образа на формирование самоотношения студентов в период обучения в вузе.

В статье излагается актуальность исследования самоотношения студентов в период раннего молодого возраста, поскольку этот период характеризуется активным межличностным взаимодействием, поиском своего места в мире и вхождением в систему общественного воспроизводства, формированием социально-нравственных оценок, уровнем социальной адаптивности посредством спортивной деятельности.

В теоретической части статьи раскрываются основные точки зрения на проблему самоотношения в челом и, в частности, подходы различных отечественных и зарубежных авторов на развитие самоотношения у студентов; отмечается влияние телесного восприятия на самоотношение у студентов, которые занимаются гендерно специфичным и гендерно неспецифичным видами спорта, то, как влияет спортивная специализация на эго-идентичность личности.

В ходе эмпирического исследования раскрываются основные закономерности самоотношения студентов вуза, занимающихся и не занимающихся спортом, связанные с самовосприятием физической и эстетической модальностей Я-образа, соотношения личностных качеств и таких показателей, как гендерная идентичность, сочиальная адаптивность, модальности Я-кониепиии. 
Приводятся результаты статистического анализа, подтверждающего достоверность проведенных исследований и правомерность сделанных выводов. В коние статьи делаются обобщающие выводы, которые дают возможность говорить о практической значимости и перспективах исследования. В качестве методического инструментария используются опросник С. Бем на гендерную идентичность, тест двадиати утверждений «Кто Я?» М. Куна и Т. МакПартленда, методика «МИС» С. Р. Пантилеева, методика «СПА» К. Роджерса и Р. Даймонд в адаптации А. К. Осницкого, тест «ДМО» Т. Лири в адаптации Л. Н. Собчик, авторский опросник Е. В. Коломийченко «Ваше отношение к спорту» для студентов, по-разному вовлеченных в спортивную деятельность, и опросники-самоописания «Я-физическое» и «Я-эстетическое».

Объектом исследования выступили студенты гуманитарных и естественнонаучных факультетов Южного федерального университета, в количестве 109 человек: 60 девушек и 49 юношей в возрасте от 18 до 22 лет, занимающихся и не занимающихся спортом; при этом учитывалось занятие гендерно специфичным и гендерно неспецифичным видами спорта.

Ключевые слова: самоотношение, индивидуальные особенности, студенты, молодежь, Я-образ, Я-концепция, физическое Я, эстетическое Я, идентичность, маскулинность, фемининность, андрогинность, сnорт, адаптация.

Для цитирования: Бабиянц К. А., Коломийченко Е. В., Хажуев И. С. Особенности самоотношения студентов вуза, занимающихся и не занимающихся спортом, в связи с самовосприятием физической и эстетической модальностей Я-образа // Российский психологический журнал. - 2017. - Т. 14. - № 1. - С. 25-38.

Материалы статьи получены 09.06.2016

UDC 159.922 .8

doi: 10.21702/rpj.2017.1.2

\title{
FEATURES OF SELF-ATTITUDE IN UNIVERSITY STUDENTS INVOLVED AND NOT INVOLVED IN SPORTS IN RELATION TO SELF-PERCEPTION OF PHYSICAL AND AESTHETIC MODALITIES OF SELF-IMAGE
}

\author{
Karine A. Babiyants ${ }^{1 *}$, Elena V. Kolomiichenko', Islam S. Khazhuev ${ }^{2}$ \\ 1 Southern Federal University, Rostov-on-Don, Russian Federation \\ ${ }^{2}$ Chechen State Pedagogical University, Grozny, Russian Federation \\ *Correspondence author. E-mail: rgupsyf@inbox.ru
}

The paper (a) examines psychological features of self-attitude in students involved and not involved in sports; (b) analyzes features of self-perception in students involved 
in gender-specific and gender-non-specific sports by means of categories of selfimage, physical self, and aesthetic self; (c) proves that bodily perception of self-image influences self-attitude in students while studying at university.

Studying students' self-attitude in early youth is of interest because it is the period of active interpersonal interaction, finding of their own place in the world, entering the system of social reproduction, forming socio-moral evaluations, social adaptation through sports activities.

The theoretical section describes the main concepts of self-attitude in domestic and foreign psychology, as well as features of the development of self-attitude in students. The analysis emphasizes the influence of (a) bodily perception on selfattitude in students involved in gender-specific and gender-non-specific sports, as well as (b) sports specialization on ego-identity of the person.

The empirical study revealed (a) the main principles of self-attitude in university students involved and not involved in sports in relation to self-perception of physical and aesthetic modalities of self-image; (b) associations among personal qualities, gender identity, social adaptiveness, and modality of self-concept.

The findings of the statistical analysis confirmed the credibility of the studies and conclusions. The final section concludes with a summary. The results are of direct practical relevance.

The methodological tools of the study included the following: (a) S. Bem Gender Identity Questionnaire; (b) M. Kuhn and T. McPartland Twenty Statements Test; (c) S. R. Pantileev technique for studying self-attitude "MIS"; (d) K. Rogers and R. Diamond technique for studying socio-psychological adaptation "SPA" (in modification of A. K. Osnitskii); (e) T. Leary Interpersonal Diagnosis (in modification of L. N. Sobchik); (f) E. V. Kolomiychenko questionnaire "Your relation to sports" for students involved in sports; (g) and "Physical Self" and "Aesthetic Self" questionnaires.

The participants comprised 109 (60 girls and 49 young men) students of sciences and humanities faculties of Southern Federal University aged 18-22 years, involved and not involved in sports.

Keywords: self-attitude, individual characteristics, students, young people, selfimage, self-concept, physical self, aesthetic self, identity, masculinity, femininity, androgyny, sports, adaptation.

For citation: Babiyants K. A., Kolomiichenko E. V., Khazhuev I. S. Features of self-attitude in university students involved and not involved in sports in relation to self-perception of physical and aesthetic modalities of self-image. Rossiiskii psikhologicheskii zhurnal - Russian Psychological Journal, 2017, V. 14, no. 1, pp. 25-38 (in Russian). 


\section{Актуальность исследования}

В отечественной психологии самосознание трактуется как часть сознания, которая осуществляется субъектом в отношении к самому себе. В отличие от других субъектов окружающего мира, оно характеризуется осознаванием своего взаимодействия с внешним миром и миром психических явлений - собственных чувств, переживаний, мыслей, действий, потребностей. В юношеском возрасте развитие самосознания особенно актуально, поскольку это время активных межличностных взаимодействий, самопознания, поиска своего места в мире, формирования социально-нравственных оценок [5, 7, 8, 22, 24, 27]. Система представлений человека о самом себе часто называется Я-концепцией, или Я-образом, она относительно устойчива и неразрывно связана с возможностью рефлексии своего существования во времени и пространстве, а также с таким феноменом, как самоотношение. Обычно такие представления имеют форму словесного обозначения, зафиксированного на уровне понятий о себе, что, по сути, является результатом познания человеком самого себя через реальный опыт, через представления и оценку себя самого в процессе соотношения с другими людьми $[4,9,11,16]$.

Самоотношение может проявляться в эмоциональном отношении к собственному Я и состоять из таких компонентов, как: самоуважение, самопринятие, любовь к себе, самооценка, самоуверенность, самоуничижение, самообвинение $[12,14,19,25,28,29,30]$. Как структура личности самоотношение формируется, прежде всего, в межличностном взаимодействии под воздействием многих внешних и внутренних психологических факторов. Одним из таких факторов является восприятие собственной телесности. Так, Т. С. Леви отмечает: «Отношение человека к своему телу является неотъемлемой частью самоотношения и аккумулирует в себе его суть» [16, с. 72]. И далее он говорит: «Отношение к своему телу чрезвычайно диагностично, так как аккумулирует в себе значимые личностные характеристики и выступает в качестве "лакмусовой бумажки" психологического здоровья человека. Чем более выражена психологическая проблема, тем более объектно отношение к телу. Так в состоянии депрессии человек воспринимает свое жизненное пространство как сузившееся, у него теряется острота чувств, изменяется ощущение своего тела» [16, с. 75]. Д. Хелл отмечает, что в экстремальном состоянии или в состоянии депрессии тело может не восприниматься как одушевленное [15]. М. М. Бахтин, В. В. Столин, - представители теории социализации в развитии Я-концепции, указывают на то, что самосознание диалогично, т. е. отношение к себе развивается и существует в форме внутреннего диалога. Поэтому способ самопрезентации может быть как субъектным, так 
и объектным, и оба они реализуются через когнитивную активность [16]. Личность по отношению к себе занимает позицию наблюдателя, дистанцируется от себя самой, и тогда самость имеет инструментальную, а не терминальную ценность. Это происходит при субъект-объектной стороне отношений, при субъект-субъектном самоотношении когнитивные процессы осуществляются со стороны внутреннего наблюдателя, и тогда вопрос звучит иначе: «Кто Я?» [13].

По мнению многих отечественных авторов, отношение человека к себе является базовым конструктом личности, поскольку влияет на установление отношений, на достижение целей, на способы формирования и достижения в кризисных ситуациях (С. Р. Пантилеев, В. В. Столин, Н. Ю. Хусаинова) $[1,2,3]$. Позитивное самоотношение базируется на вере человека в собственные силы, в свою самостоятельность, обусловливает меньшее поглощение своими внутренними проблемами, снижает частоту психосоматических расстройств (Д. В. Желателев, А. П. Корнилова, О. Г. Лопухова, Г. И. Морева, Т. П. Шарай, С. Г. Якобсон) [6, 17, 18, 20, 21, $23,26,31]$.

\section{Объект, предмет и методы исследования}

Характеристика самоотношения у студентов вуза часто связана с представлением о своих Я-физическом и Я-эстетическом телесных образах, поэтому мы предположили, что занятия спортом могут оказывать существенное влияние на самоотношение студентов вуза и, по сути, являться средством социализации студентов через изменение их образа телесности, что, в свою очередь, зависит от степени вовлеченности молодежи в спортивную деятельность или физическую культуру. Наиболее важным моментом, на наш взгляд, является предположение о том, что самоотношение студентов вуза может быть связано с дифференциацией Я-физического и Я-эстетического как модальностей образа телесности, в зависимости от вовлеченности их в спортивную деятельность. Модальности телесности, в свою очередь, могут иметь различную выраженность в структуре самоотношения у студентов вуза с различной половой принадлежностью, занимающихся гендерно специфичными и гендерно неспецифичными видами спорта.

В качестве диагностического инструментария мы использовали тест С. Бем на выраженность гендерной идентичности, тест М. Куна и Т. МакПартленда «Кто Я?», тест Т. Лири «ДМО» в адаптации Л. Н. Собчик, методику С. Р. Пантилеева «МИС», методику «СПА» К. Роджерса и Р. Даймонд в адаптации К. Осницкого [10]. Также нас интересовали аспекты осознавания студентами собственного отношения к спорту и представления 
о собственном физическом и эстетическом образах. С целью исследования этих аспектов осознанности самоотношения был разработан авторский опросник Е. В. Коломийченко «Ваше отношение к спорту» для студентов, по-разному вовлеченных в спортивную деятельность, и опросники-самоописания «Я-физическое» и «Я-эстетическое» [12].

Объектом исследования выступили студенты гуманитарных и естественнонаучных факультетов Южного федерального университета в г. Ростовена-Дону, общим количеством 109 человек, из которых 60 девушек, 49 юношей в возрасте от 18 до 22 лет, занимающихся спортом и имеющих высокие спортивные достижения, и не занимающихся спортом.

В ходе исследования нами было установлено, что модальности телесности, такие как Я-эстетическое и Я-физическое, имеют различное значение для юношей и девушек. Так, для девушек модальность «Я-эстетическое» наиболее значима, вне зависимости от того, занимаются или не занимаются они спортом, а также независимо от их гендерной идентичности в спорте. Тот же вывод правомерен и для юношей, занимающихся гендерно неспецифичным видом спорта, таким, например, как чирлидинг. У юношей, занимающихся гендерно специфичным видом спорта (волейбол, футбол, тяжелая атлетика), напротив, важным компонентом телесности является Я-физическое. Некоторые закономерности обнаружены у студентов, юношей и девушек, которые не занимаются спортом. У них самоотношение осуществляется безотносительно модальностей телесности, но через когнитивные и коммуникативные характеристики. Также было выявлено, что различение модальностей «Я-физическое» и «Я-эстетическое» зависит от того, насколько интенсивно студенты занимаются спортом. Например, студенты-спортсмены высокой квалификации практически не дифференцируют модальности «Я-физическое» и «Я-эстетическое», их самоотношение характеризуется единством этих двух модальностей телесности. У студентов, занимающихся спортом на любительской основе, отличается модальность телесности, особенно актуально восприятие Я-физического для девушек. Студенты, которые не занимаются спортом, имеют ярко выраженные отличия в понимании Я-физического и Я-эстетического аспектов телесности. В высказываниях описательного характера они характеризуют Я-физическое через показатели силы, выносливости, мощи, выдержки, а Я-эстетическое - через показатели красоты, внешней привлекательности, подтянутости, красоты форм и линий.

Также было установлено, что такие показатели самоотношения, как «самопринятие», «самоценность», «самоуверенность» напрямую связаны с характером и интенсивностью спортивной нагрузки. Например, у всех девушек и юношей, безотносительно к занятиям спортом, уровень 
интернальности выражен нормативными показателями; занимающиеся спортом юноши не имеют склонности к эскапизму (уходу от реальности) и самореализуются в процессе занятий спортом. Студенты, которые занимаются гендерно неспецифичным спортом, проявляют тенденцию к внутренней конфликтности, недовольству собой, они стремятся к изменению собственного физического образа Я. По данным статистики, наиболее адаптивными являются юноши и девушки, занимающиеся спортом (показатель «адаптивность» равен 10.307, при $p=0.035)$. Им свойственны «эмоциональная комфортность» (18.751, при $р=0.008)$ и «самопринятие» (57.362, при $\mathrm{p}=1.039 \mathrm{e}-11)$.

Достаточно интересным выводом стало то, что для юношей, занимающихся гендерно неспецифичным спортом (чирлидинг) и не занимающихся спортом, отсутствие адекватной физической нагрузки приносит больший вред в формированиии самоотношения, чем для девушек. Так, применив статистические процедуры, мы получили значимые различия в самоотношении у студентов обоих полов, занимающихся гендерно неспецифичными видами спорта по шкалам «Я-идеальное» и «Я-реальное». Например, по показателям: «агрессивность» $(\mathrm{W}=139, \mathrm{p}$-value = 0.009323), «альтруистичность» $(\mathrm{W}=132, \mathrm{p}$-value $=0.005974)$, «эгоистичность» $(\mathrm{W}=111$, p-value $=0.006453)$.

Анализ результатов авторских опросников «Ваше отношение к спорту», «Я-физическое» и «Я-эстетическое» подтверждает тенденцию к уменьшению эго-идентичности, выраженной «присоединяющими» понятиями по мере снижения физической нагрузки у юношей и девушек. В то же время дифференцирующая эго-идентичность нарастает по мере снижения физической спортивной нагрузки и имеет прямое отношение к эстетическому аспекту телесного образа Я. У студентов обоих полов, занимающихся спортом, спортивная эго-идентичность соотносится с ролью спортсмена или спортсменки и указывает на ориентацию на здоровый образ жизни. Статистический анализ достоверно подтвердил наличие разницы в самоотношении между группами испытуемых юношей и девушек, занимающихся и не занимающихся спортом, по следующим шкалам: «самоуверенность» (p-value $=0.006696$, при $p \leq 0.05)$, «самоценность» $(p$-value $=0.009036$, при $p \leq 0.05)$, «самопринятие» ( $\mathrm{p}$-value $=0.002242$, при $\mathrm{p} \leq 0.05)$, «самопривязанность» (p-value $=0.02688$, при $\mathrm{p} \leq 0.05)$, «конфликтность» (p-value = 1.12e-07, при $p \leq 0.001)$, «самообвинение» $(p$-value $=0.04716$, при $\mathrm{p} \leq 0.05)$.

Было выявлено достоверное отличие студентов, занимающихся чирлидингом, от студентов, занимающихся волейболом ( $\mathrm{t}=0.00057)$, не занимающихся студентов ( $\mathrm{t}=0.00610)$, студентов, имеющих любительскую физическую 
нагрузку $(\mathrm{t}=0.00126)$. Внутренняя конфликтность ниже у студентов, занимающихся спортом, по сравнению со студентами, не занимающимися спортом ( $\mathrm{t}=6 \mathrm{e}-09)$, а также у студентов, занимающихся гендерно специфичным видом спорта, в отличие от студентов, занимающихся гендерно неспецифичным видом спорта $(\mathrm{t}=7 \mathrm{e}-06)$.

Относительно гендерной выраженности у девушек и юношей, студентов вуза, мы пришли к выводу, что в большинстве случаев и независимо от того, занимаются ли они спортом, характерен андрогинный тип гендерной идентичности. Но мы также можем говорить о тенденции увеличения андрогинности у юношей, занимающихся гендерно специфичными видами спорта (баскетбол, футбол, тяжелая атлетика), и о тенденции к увеличению фемининности у юношей, занимающихся гендерно неспецифичными видами спорта (чирлидинг), а также у не занимающихся спортом юношей (Kruskal - Wallis, критерий X-squared $=16.681$, df = 8, $\mathrm{p}$-value $=0.0336)$.

\section{Практическая значимость и перспектива исследования}

Практическая значимость исследования заключается в возможности создать практические рекомендации по формированию подходов к развитию позитивного самоотношения у студентов вуза, научить их понимать себя, рефлексировать внешние и внутренние события жизни, понимать мотивы поведения значимых и незначимых других, адекватно и конструктивно взаимодействовать с ними, обретая ценность собственного Я и осознавая ее как таковую. Перспективой исследования для нас является изучение самоотношения у студентов вузов в регионах России с различными этноконфессиональными и культурными особенностями и различным статусом безопасности (конфликтный, постконфликтный, неконфликтный, пограничный регионы).

\section{Выводы}

В результате проведенных исследований мы можем сделать вывод, что, во-первых, физическая культура и спорт оказывают непосредственное влияние на самоотношение студентов-спортсменов вуза и студентов, не занимающихся спортом, посредством изменения их образа телесности. У студентов вуза, занимающихся спортом и имеющих целью достижение высоких спортивных результатов, доминирует высокая выраженность «присоединяющей» эго-идентичности, связанной со статусом «спортсмен», с установкой на здоровый и активный образ жизни. У не занимающихся студентов доминирует «дифференцирующая» эго-идентичность, не имеющая отношение к телесному образу. 
Во-вторых, самоотношение студентов-спортсменов вуза высшей квалификации связано с дифференциацией Я-физического и Я-эстетического как модальностей образа телесности, в зависимости от степени интенсивности занятий спортом. Чем выше интенсивность занятий спортом, тем меньше дифференциация, когда Я-физическое и Я-эстетическое воспринимаются как единый компонент. Чем ниже интенсивность, тем более выражена дифференциация, при этом у юношей показатели самоотношения связаны с присоединяющей идентичностью Я-физического, а у девушек - с дифференцирующей эго-идентичностью Я-эстетического.

В-третьих, модальности телесности имеют различную выраженность в структуре самоотношения у юношей и девушек, занимающихся гендерно специфичными или гендерно неспецифичными видами спорта. Модальность «Я-эстетическое» значима для девушек, независимо от уровня интенсивности занятий спортом и гендерной спортивной идентичности, и для юношей, которые занимаются гендерно неспецифичным видом спорта (чирлидинг). В переживании эмоционального комфорта как компонента самоотношения у девушек и юношей-спортсменов высшей квалификации участвуют различные механизмы: у юношей спорт является механизмом самореализации и достижения эмоционального равновесия, разрядки и удовлетворения в результате значимых достижений, а у девушек доминирует эстетический компонент самоотношения.

В-четвертых, самоотношение у студентов-спортсменов вуза высшей квалификации и студентов, не занимающихся спортом, по-разному влияет на их социальную адаптацию. У занимающихся спортом студентов и не занимающихся спортом девушек социальная адаптация выражена нормативными показателями. У не занимающихся спортом юношей чаще формируется фемининная гендерная идентичность, что отражается на общем снижении самоотношения и порождает внутреннее напряжение и неудовлетворенность, нарушение механизмов самореализации и достижения эмоционального равновесия, которое тесно связано с психологией достижений у юношей. У них отсутствует гармоничная разница между показателями «Я-реальное» и «Я-идеальное», и есть высокая невротизирующая тенденция к изменению Я-идеального: стремление снизить агрессивность и недоверчивость (40\%), снизить осторожность (50\%), изменить стиль межличностного взаимодействия в сторону снижения ответственности за других, нежелания решать чужие проблемы (60\%), в сторону индивидуалистичности и эгоизма.

\section{Литература}

1. Аварханов М. А. Формирование здорового образа жизни студенческой молодежи в процессе физического воспитания // Актуальные проблемы 
физической культуры и спорта: сборник научно-методических трудов профессорско-преподавательского коллектива, аспирантов, соискателей и студентов / Под ред. Т. К. Ким, Г. А. Кузьменко. - М.: Прометей, 2013. - С. 6-8.

2. Акчурин Б. Г. Телесность как проявление человеческого потенциала // Социально-гуманитарные знания. - 2004.- № 2. - С. 31-37.

3. Арина Г. А., Николаева В. В. Психология телесности: методологические принципы и этапы клинико-психологического анализа // Психология телесности между душой и телом / Ред.-сост. В. П. Зинченко, Т. С. Леви. М.: АCT, 2007. - С. 222-235.

4. Бабияни К. А., Мануйлова О. В. Формирование когнитивного аспекта самосознания молодежи по средствам развития рефлексии в фрустрирующей ситуации // Международный форум по когнитивному моделированию (IFCM-2013), Милано-Мариттима. - Ростов н/Д: Изд-во СКНЦ ВШ ЮФУ, 2013. - С. 251-255.

5. Багадирова С. К., Юрина А. А. Материалы к курсу «Психология личности»: учебное пособие: в 2-х ч. - М.: Директ-Медиа, 2014. - Ч. 2. - 172 с.

6. Буренкова Е. В. Образ Я как оценка собственной внешности девушками 17-18 лет. - Пенза: Изд-во ПГУ, 2008. - С. 8.

7. Волкова Т. Г. Психология самосознания: учебное пособие. - М.: ДиректМедиа, 2013. - 296 с.

8. Иванова В. В. Общие вопросы самосознания личности. - М.: Прометей, 2014. - $152 \mathrm{C}$.

9. Иващук О. Ф. «Я» как понятийная форма. - М.: Директ-Медиа, 2014. - 313 с.

10. Касьяник Е. Л., Макеева Е. С. Психологическая диагностика самосознания личности. - Мозырь: Содействие, 2007. - 224 с.

11. Кибальченко И. А., Кондракова Н. В. Изучение потенциальных ресурсов у студентов в аспекте саморазвития, самоорганизации и самоопределения молодежи // Человек, субъект, личность в современной психологии: Материалы Международной конференции, посвященной 80-летию А. В. Брушлинского / Отв. ред. А. Л. Журавлев, Е. А. Сергиенко. М.: Изд-во Института психологии РАН, 2013. - Т. 3. - С. 52.

12. Коломийченко E. В. Самоотношение и гендерная идентичность как факторы формирования образа телесности у современной молодежи // Теория и практика общественного развития. - 2015. - № 16. - С. 268-272.

13. Кон И. Мужские исследования: меняющиеся мужчины в изменяющемся мире // Введение в гендерные исследования / Под ред. И. Жеребкиной. - Харьков, 2001.

14. Корнилова А. П., Якобсон С. Г., Морева Г. И., Шарай Т. П. Влияние отношения к своему телу и половой принадлежности на самоотношение личности. - П.: Изд-во ПГУ, 2008. - С. 91. 
15. Кухтерина А. Н. Латентная иерархия мотивов участия студенческой молодежи в спортивной деятельности // Актуальные проблемы физической культуры и спорта: сборник научно-методических трудов профессорско-преподавательского коллектива, аспирантов, соискателей и студентов / Под ред. Т. К. Ким, Г. А. Кузьменко. - М.: Прометей, 2013. - С. 143-144.

16. Леви Т. С. Отношение к телу в структуре самоотношения // Знание. Понимание. Умение. - 2008. - № 3. - С. 72-75.

17. Мануйлова О. В. Индивидуальная профильная асимметрия как показатель результативности спортивной деятельности в гребле на каноэ // Материалы XXXVII научной конференции сотрудников, аспирантов и студентов факультета психологии ЮФУ, 20-21 апреля. - М.: КРЕДО, 2009. - С. 342-343.

18. Новицкая М. С. Психологические аспекты танцевального спорта в системе спортивной подготовки // Психология обучения. - 2014. - № 7. С. 87-93.

19. Психология телесности /Под ред. В. П. Зинченко, Т. С. Леви. - М., 2011.- 731 с.

20. Потехина Л. М., Ганченко Н. М., Чумакова 3. В. Волейбол как средство развития коммуникативных способностей // Актуальные проблемы физической культуры и спорта: сборник научно-методических трудов профессорско-преподавательского коллектива, аспирантов, соискателей и студентов. - М.: Прометей, 2013. - С. 187-190.

21. Трусова Н. В., Бараборкина Л. Н., Сапего А. В., Козырева Е. В. Техническая подготовка игроков в женском футболе // Вестник Кемеровского государственного университета. - 2014. - Т. 2. - № 4 (60). - С. 91-95.

22. Уляева Л. Г. Я-физическое в структуре самосознания. - М., 2012. - 234 с.

23. Цикунова Н. С. Гендерные характеристики личности спортсменов в маскулинных и феминных видах спорта: автореф. дисс. ... канд. психол. наук. - СПб., 2003. - 20 с.

24. Abbott B. D., Barber B. L. Differences in functional and aesthetic body image between sedentary girls and girls involved in sports and physical activity: Does sport type make a difference? // Psychology of Sport and Exercise Journal. - 2011. - no. 12. - pp. 333-342.

25. Maro C., Roberts G. Gender differences on cognitive, motivation and affective responses within Tanzanian physical education context. An achievement goal approach // Athens 2004: Pre-olympic Congress. Sport Science Through the Ages: Challenges in the New Millennium. - Thessaloniki, 2004. - V. 1. - URL: http://cev.org.br/biblioteca/gender-differences-on-cognitive-motivationaland-affective-responses-within-tanzanian-physical-education-context-anachievement-goal-approach 
26. McDougal J. Participation in sport and sex discrimination // 2004 Pre-Olympic Congress. - Thessaloniki, 2004. - V. 1. - p. 136.

27. Monterio Gaspar M. J., Amaral T. F., Oliveira B. M. P. M., Borges N. Protective effect of physical activity on dissatisfaction with body image in children A cross-sectional study // Psychology of Sport and Exercise Journal. 2011. - no. 12. - pp. 563-569.

28. Pfister G. Gender, sport and health - changing discourses // 2004 Pre-Olympic Congress. - Thessaloniki, 2004. - V. 1. - pp. 124-125.

29. Popovic R., Kocic J., Herodek K., Muratidou E., Damjanovska M. Barriers to women participation in sport and recreation from perspective of underprivileged and developed countries // 2004 Pre-Olympic Congress. - Thessaloniki, 2004. - V. 1. - p. 494.

30. Tosunidis A., Pappas C., Zarotis G. Sex characteristics of motives in university sport and fitness center // 2004 Pre-Olympic Congress. - Thessaloniki, 2004. - V. 1. - p. 15.

31. Volkwein-Caplan K. A. E. Homophobia in women's sport // 2004 Pre-Olympic Congress. - Thessaloniki, 2004. - V. 1. - pp. 124-164.

\section{References}

1. Averianov M. A. Forming healthy lifestyle in students in physical education. In: Aktual'nye problemy fizicheskoi kul'tury i sporta [Urgent problems of physical culture and sports]. Moscow, Prometei Publ., 2013, pp. 6-8.

2. Akchurin B. G. Physicality as a manifestation of human potential. Social'nye igumanitarnye znanija, 2004, no. 2, pp. 31-37 (in Russian).

3. Arina G. A., Nikolaeva V. V. Psychology of physicality: methodological principles and stages of clinical and psychological analysis. In: Psikhologiya telesnosti mezhdu dushoi i telom [Psychology of physicality between soul and body]. Moscow, AST Publ., 2007, pp. 222-235.

4. Babiyants K. A., Manuilova O. V. Forming a cognitive aspect of self-consciousness in young people by developing reflection in frustrating situations. In: Mezhdunarodnyi forum po kognitivnomu modelirovaniyu (IFCM-2013) [International forum on cognitive modeling (IFCM-2013)]. Rostov-on-Don, SKNTs VSh YuFU Publ., 2013, pp. 251-255.

5. Bagadirova S. K., Yurina A. A. Materialy k kursu «Psikhologiya lichnosti» [Personality psychology]. Moscow, Direkt-Media Publ., 2014, Part 2. 172 p.

6. Burenkova E. V. Obraz Ya kak otsenka sobstvennoi vneshnosti devushkami 17-18 let [Self-image as assessing of own appearance in girls aged 17-18 years]. Penza, Penza State University Publ., 2008, p. 8.

7. Volkova T. G. Psikhologiya samosoznaniya [Psychology of self-consciousness]. Moscow, Direkt-Media Publ., 2013. 296 p. 
8. Ivanova V. V. Obshchie voprosy samosoznaniya lichnosti [Common issues of self-consciousness]. Moscow, Prometei Publ., 2014. 152 p.

9. Ivashchuk O. F. «Ya» kak ponyatiinaya forma [Self as a conceptual form]. Moscow, Direkt-Media Publ., 2014. 313 p.

10. Kas'yanikE. L., Makeeva E. S. Psikhologicheskaya diagnostika samosoznaniyalichnosti [Psychological diagnostics of self-consciousness]. Mozyr', Sodeistvie Publ., 2007.224p.

11. Kibal'chenko I. A., Kondrakova N. V. Izuchenie potentsial'nykh resursov u studentov $v$ aspekte samorazvitiya, samoorganizatsii i samoopredeleniya molodezhi [Studying potential resources in students from the aspect of self-development, self-organization, and self-determination of young people]. Chelovek, sub"ekt, lichnost' v sovremennoi psikhologii: Materialy Mezhdunarodnoi konferentsii, posvyashchennoi 80-letiyu A. V. Brushlinskogo [Proc. the International Conference on the 80th anniversary of A. V. Brushlinskii “Man, subject, and personality in modern psychology"]. Moscow, Institute of Psychology RAS Publ., 2013, V. 3. 52 p.

12. Kolomiichenko E. V. Self-attitude and gender identity as factors forming the image of physicality in modern young people. Teoriya i praktika obshchestvennogo razvitiya - Theory and Practice of Social Development, 2015, no. 16, pp. 268-272 (in Russian).

13. Kon I. Men's studies: changing men in a changing world. In: Vvedenie $v$ gendernye issledovaniya [Introduction to gender studies]. Kharkov, 2001.

14. Kornilova A. P., Yakobson S. G., Moreva G. I., Sharai T. P. Vliyanie otnosheniya $k$ svoemu telu i polovoi prinadlezhnosti na samootnoshenie lichnosti [The influence of relation to own body and gender on self-attitude of the person]. Perm, PSU Publ., 2008. 91 p.

15. Kukhterina A. N. Latent hierarchy of motives of students' involvement in sports activities. In: Aktual'nye problemy fizicheskoi kul'tury i sporta [Urgent problems of physical culture and sports]. Moscow, Prometei Publ., 2013, pp. 143-144.

16. Levi T. S. Relation to the body in the structure of self-attitude. Znanie. Ponimanie. Umenie. - Kowledge. Understanding. Skill, 2008, no. 3, pp. 72-75 (in Russian).

17. Manuilova O. V. Individual'naya profil'naya asimmetriya kak pokazatel' rezul'tativnosti sportivnoi deyatel'nosti v greble na kanoe [Individual profile asymmetry as a parameter of the effectiveness of canoeing]. Materialy XXXVII nauchnoi konferentsii sotrudnikov, aspirantov i studentov fakul'teta psikhologii YUFU [Proc. 37th scientific conference of academic staff, postgraduates and students of psychology faculty of Southern Federal University in 20-21 April]. Moscow, KREDO Publ., 2009, pp. 342-343.

18. Novitskaya M. S. Psychological aspects of dance sport in the system of sports training. Psikhologiya obucheniya - Educational Psychology, 2014, no. 7, pp. 87-93 (in Russian). 
19. Zinchenko V. P., Levi T. S. (eds.) Psikhologiya telesnosti [The psychology of physicality]. Moscow, $2011.731 \mathrm{p}$.

20. Potekhina L. M., Ganchenko N. M., Chumakova Z. V. Volleyball as a means of developing communicative abilities. In: Aktual'nye problemy fizicheskoi kul'tury i sporta [Urgent problems of physical culture and sports]. Moscow, Prometei Publ., 2013, pp. 187-190.

21. Trusova N. V., Baraborkina L. N., Sapego A. V., Kozyreva E. V. Technical training of players in women's football. Vestnik Kemerovskogogosudarstvennogo universitetaBulletin of Kemerovo State University, 2014, V. 2, no. 4 (60), pp. 91-95 (in Russian).

22. Ulyaeva L. G. Ya-fizicheskoe $v$ strukture samosoznaniya [Physical self in the structure of self-consciousness]. Moscow, 2012. 234 p.

23. Tsikunova N. S. Gendernye kharakteristiki lichnosti sportsmenov v maskulinnykh ifeminnykh vidakh sporta [Gender characteristics of athletes in the masculine and feminine sports]. Diss. Cand. Sci. (Psych.). St. Petersburg, 2003.

24. Abbott B. D., Barber B. L. Differences in functional and aesthetic body image between sedentary girls and girls involved in sports and physical activity: Does sport type make a difference? Psychology of Sport and Exercise Journal, 2011, no. 12, pp. 333-342.

25. Maro C., Roberts G. Gender differences on cognitive, motivation and affective responses within Tanzanian physical education context. An achievement goal approach. In: Athens 2004: Pre-olympic Congress. Sport Science Through the Ages: Challenges in the New Millennium. Thessaloniki, 2004, V. 1. URL: http://cev.org.br/biblioteca/gender-differences-on-cognitive-motivationaland-affective-responses-within-tanzanian-physical-education-context-anachievement-goal-approach

26. McDougal J. Participation in sport and sex discrimination. In: 2004 PreOlympic Congress. Thessaloniki, 2004, V. 1, p. 136.

27. Monterio Gaspar M. J., Amaral T. F., Oliveira B. M. P. M., Borges N. Protective effect of physical activity on dissatisfaction with body image in children - A crosssectional study. Psychology of Sport and Exercise Journal, 2011, no. 12, pp. 563-569.

28. Pfister G. Gender, sport and health - changing discourses. In: 2004 PreOlympic Congress. Thessaloniki, 2004, V. 1, pp. 124-125.

29. Popovic R., Kocic J., Herodek K., Muratidou E., Damjanovska M. Barriers to women participation in sport and recreation from perspective of underprivileged and developed countries. In: 2004 Pre-Olympic Congress. Thessaloniki, 2004, V. 1, p. 494.

30. Tosunidis A., Pappas C., Zarotis G. Sex characteristics of motives in university sport and fitness center. In: 2004 Pre-Olympic Congress. Thessaloniki, 2004, V. 1, p. 15.

31. Volkwein-Caplan K. A. E. Homophobia in women's sport. In: 2004 Pre-Olympic Congress. Thessaloniki, 2004, V. 1, pp. 124-164. 